\title{
Graphene doped with silver nanoparticle as p-type dopants in efficient perovskite solar cells
}

\author{
N. Ismail ${ }^{1 *}$, E.A. El-Sharkawy ${ }^{2}$, Mohamed S. Soltan ${ }^{2}$, Reda F. M. Elshaarawy ${ }^{2}$, Hassan M. A. \\ Hassan ${ }^{2,3^{*}}$ \\ ${ }^{1}$ Physical Chemistry Department, Centre of Excellence for Advanced Sciences, Renewable Energy Group, National \\ Research Centre, 12311, Dokki, Giza, Egypt \\ ${ }^{2}$ Department of Chemistry, Faculty of Science, Suez University, Suez, Egypt \\ ${ }^{3}$ Department of Chemistry, College of Science, Jouf University, PO Box 2014, Sakaka, Saudi Arabia
}

\section{ARTICLE INFO}

\section{Article history:}

Received 4 March 2020

Received in revised form 28 March 2020

Accepted 3 April 2020

Available online 12 April 2020

\section{Keywords}

p- type,

Perovskite,

Graphene,

silver nanoparticles,

\begin{abstract}
Perovskite materials have been shown to be involved in energy conversion and environmental applications. Graphene doped with silver nanoparticle (Ag@G) is designed and synthesized for the first time as p-type dopants in solid-state perovskite solar cells (PSCs) applications. The fabricated nanocomposite was emphasized by Xray diffraction (XRD), Raman spectroscopy and field emission scanning electron microscopy (FESEM). By characterizing the optical and electrochemical properties, graphene doped with silver nanoparticles is eligible for oxidation of $N^{2}, N^{2}, N^{2^{\prime}}, N^{2^{\prime}}, N^{7}, N^{7}, N^{7^{\prime}}, N^{7^{\prime}}$-octakis(4-methoxyphenyl)-9,9'-spirobi[9H-fluorene]-2,2', 7,7'tetramine (Spiro-OMeTAD), the commonly used hole-transport material (HTM). The results revealed that the Ag@G nanocomposite was successfully synthesize. Furthermore, the efficiency of PSCs as high as 10 percent was achieved when the prepared material was applied as a p-type. This could be attributed to the boosting of the charge carrier transfer between the absorbing layer and the fabricated material. Therefore, the fabricated Ag@G nanocomposite is a promising candidate for a solar cell technology as a p-type dopant.
\end{abstract}

\section{Introduction}

Perovskite solar cells (PSCs) are rapidly growing as the most innovative photovoltaic technologies, grabbing attention in the world energy situation and drawing the attention of the scientific community to establish effective and stable perovskite-based devices [1-10]. Methylammonium lead triiodide $\left(\mathrm{CH}_{3} \mathrm{NH}_{3} \mathrm{Pbl}_{3}\right)$, the most popular perovskite, is featured by high mobility, outstanding absorption coefficient, durability of band gaps, long diffusion length and low cost of material [11-16], making perovskite material potentially promising in the PV field. Two types of architectures have now been adopted for perovskite solar cells.

One is a mesostructured solar cell composed of semiconducting metal oxides $\left(\mathrm{TiO}_{2}, \mathrm{ZnO}_{2}\right.$, etc.) with a mesoporous $(\mathrm{mp})$ electron transport layer (ETL). The other is a solar cell structured $p-i-n$ or $p-n$ junction planar without the mp-ETL [17]. Graphene and associated twodimensional components have recently been implemented into the device framework to enhance load injection and/or electrode collection: an increase in power conversion efficiency and long-term stability [18] has been achieved.

\footnotetext{
* Corresponding authors:

E-mail addresses: nahlaismail24@yahoo.com (N. Ismail) hmahmed@ju.edu.sa (Hassan M. A. Hassan)
}

Indeed, interfaces between perovskite and transportation layers have lately been shown to have a drastic effect on the recombination of load and material instability processes within the operating machine. Nonetheless, if available charges are easily introduced into the transport layer of the electron from perovskite, degradation of perovskite is delayed and non-radiative recombination is decreased.

In general, the introduction of ( $\mathrm{Ag} @ \mathrm{G})$ into the perovskite solar cell as the HTL finely increase cell conversion efficiency (11 percent) by illustrating the primary function of graphene interface design in perovskite-based devices [19]. Therefore, to finely increase the photovoltaic efficiency of devices, the impact of graphene-modified matrix (Ag@G) on the perovskite solar cell needs to be assessment in more detail.

Herein, we report the facile approach for the fabrication (Ag@G) composite. The performance of the fabricated Ag@G composite in solid-state perovskite solar cells (PSCs) as p-type dopants is reported. 


\section{Materials and methods}

\subsection{Materials}

All the chemicals were analytical pure. Graphite powder, $\mathrm{NaNO}_{3}$, potassium permanganate, $\mathrm{H}_{2} \mathrm{O}_{2}$, sulphuric acid, $\mathrm{HCl}, \mathrm{AgNO}_{3}$ was obtained from Sigma-Aldrich. All reagents were applied without further purification.

\subsection{Materials Fabrication}

The literature indicates that methylammonium iodide (MAI) has been synthesized as described in the previous work [20]. Graphene oxide was prepared using modified hummer method in this work. The following procedure was used to prepare $\mathrm{Ag}$ with reduced graphene oxide composite (Ag@G). GO dispersion was permitted for $1 \mathrm{~h}$ to sonicate. Then, under continuous stirring for $1 \mathrm{~h}$, a required amount of $\mathrm{AgNO}_{3}$ solution was slowly added to the $\mathrm{GO}$ suspension. The product was stirred for 3 hours; the slurry obtained was transferred to an autoclave of $50 \mathrm{~mL}$ Teflonlined stainless steel and heated for 6 hours to $150^{\circ} \mathrm{C}$. The superannuated liquid was discarded after the reaction and the precipitate has been cooled to room temperature washed with water, centrifuged and dried in a $55^{\circ} \mathrm{C}$ oven and labeled as composite (Ag@G).

\subsection{Characterization}

With a Renishaw confocal Raman microscope, Raman was obtained using a $514 \mathrm{~nm}$ excitation line with a 100X objective lens and $1 \mathrm{~mW}$ as an incident intensity. PANALYTICAL X-Ray Diffractometer (XRD) with copper $\mathrm{Cu} \mathrm{Ka}$ radiation $(30 \mathrm{~mA}, 40 \mathrm{kV})$ to assess and determine the crystalline phases. Field emission scanning electron microscope (JOEL JSM-7500 FA) emphasized the morphology of the prepared materials. PL assessments were carried out in a quasi-back-scattering system, holding the samples in a closed cycle cryostat and increasing the temperature from 10 to $300 \mathrm{~K}$. (J- V) curves, were assessed from a Newport 91160A 300 W Solar Simulator (Class A) in a nitrogen filled glove box using a Keithley 2400 source meter with standard 1 sun AM 1.5 simulated solar irradiation $\left(100 \mathrm{~mW} \mathrm{~cm}^{-2}\right)$.

\subsection{Cell fabrication}

The glass substrate coated with indium tin oxide (ITO) and exhibit with a sheet resistance of $\sim 10 \Omega$ sq-1 was cleaned with soap, sonicated in acetone and ethanol and then dried by nitrogen. To prepare mesoporous $\mathrm{TiO}_{2}$ dilute Titanium diisopropoxide acetyle acetone (TiAA) with ethanol (for $0.1 \mathrm{M}, 1: 19 \mathrm{vol} / \mathrm{vol}$, for $0.3 \mathrm{M}, 1: 6 \mathrm{vol} / \mathrm{vol}$ ), spincast $0.1 \mathrm{M} \mathrm{TiAA}$ at $5000 \mathrm{rpm}$ for $30 \mathrm{sec}$, after that dry on hot plate at $100{ }^{\circ} \mathrm{C}$ for $5 \mathrm{~min}$, finally Sinter in furnace at 500 ${ }^{0} \mathrm{C}$ for $30 \mathrm{~min}$. (The temperature is raised gradually.) Dissolve $\mathrm{Pbl}_{2}$ (Sigma Aldrich, $99.999 \%$ ) and $\mathrm{CH}_{3} \mathrm{NH}_{3} \mathrm{I}$ in anhydrous DMF at $45 \mathrm{wt} \%$ (molar ratio 1:1), (DMF $1 \mathrm{ml}$ ), stir the precursor solution for $30 \mathrm{~min}$ spin-cast the precursor solution at $6500 \mathrm{rpm}$ for $4 \mathrm{sec}$, ramp time is 0.5 $\mathrm{sec}$, then dry and anneal on hot plate at $100^{\circ} \mathrm{C}$ for $10 \mathrm{~min}$. To prepare hole transport layer suspension solution of (Ag@G) three times and dried well. Finally coat with carbon paste as cathode.

\section{Result and Discussion}

\subsection{X-Ray diffraction investigation}

Fig.1 shows the XRD pattern of the synthesized Ag@G. The fabricated Ag@G nanocomposite exhibited four diffraction peaks displayed at $38.1^{\circ}, 44.42^{\circ}, 64.5^{\circ}$, $77.5^{\circ}$, which were ascribed to the characteristics metallic silver (111), (200), (220), and (311), crystal planes respectively suggesting the existence of $\mathrm{Ag}$ metal in the composite [21].

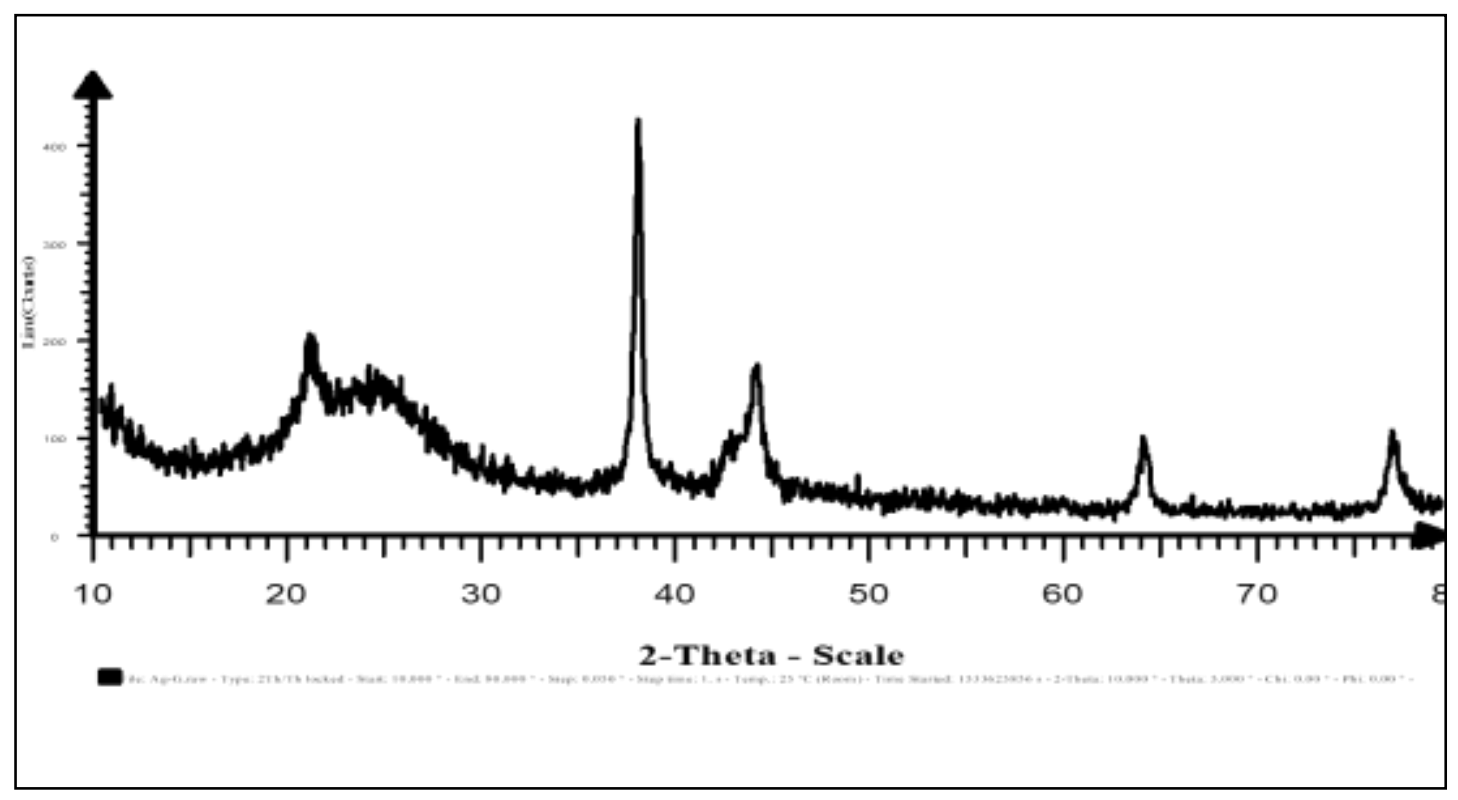

Fig.1. XRD patterns (Ag@G) nanocomposite. 


\subsection{Raman Assessment}

The Fig.2 displays the Raman spectra of (Ag@G) nanocomposite. It is noted that the composite exhibits a $G$ band at $1587 \mathrm{~cm}^{-1}$ and $D$ band at $1349 \mathrm{~cm}^{-1}$, respectively. The intensity disorder ratio is higher after hydrothermal treatment (ID/IG=0.99) which further confirmed the reduction [22]. Raman spectra confirmed the formation of crystalline $\mathrm{Ag}$ with graphene during hydrothermal treatment.

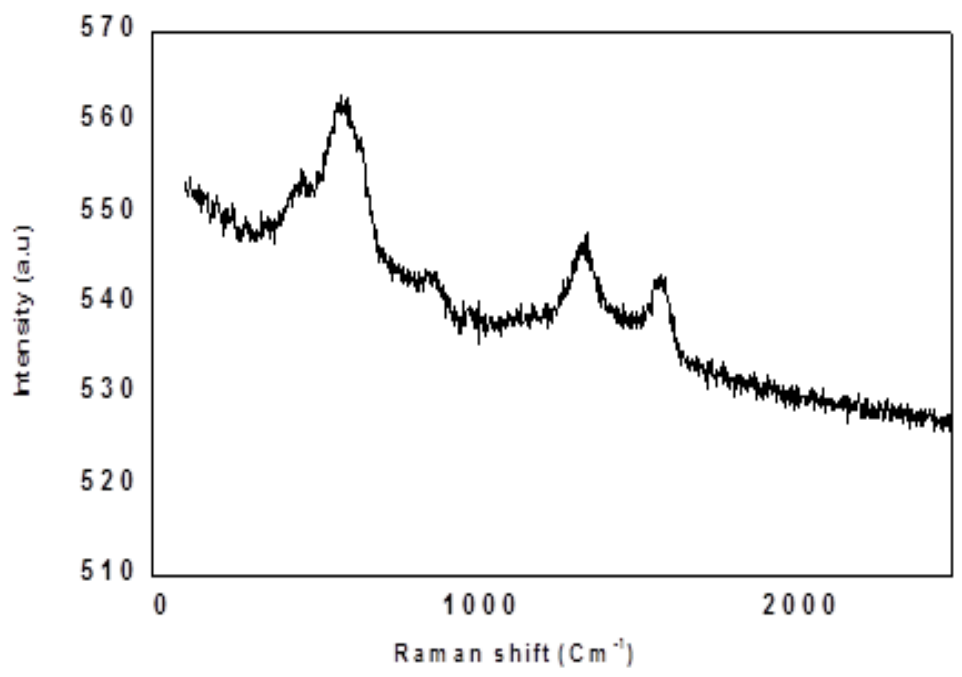

Fig.2. Raman spectra of $\mathrm{Ag} @ \mathrm{G}$ nanocomposite

\subsection{SEM Investigation}

Scanning electron microscope (SEM) investigated the morphology of the synthesized composite. Fig. 3 shows the nanocomposite SEM image. It displays a uniform AgNP decoration on the sheets of graphene. The average particle size is approximately $21 \mathrm{~nm}$.

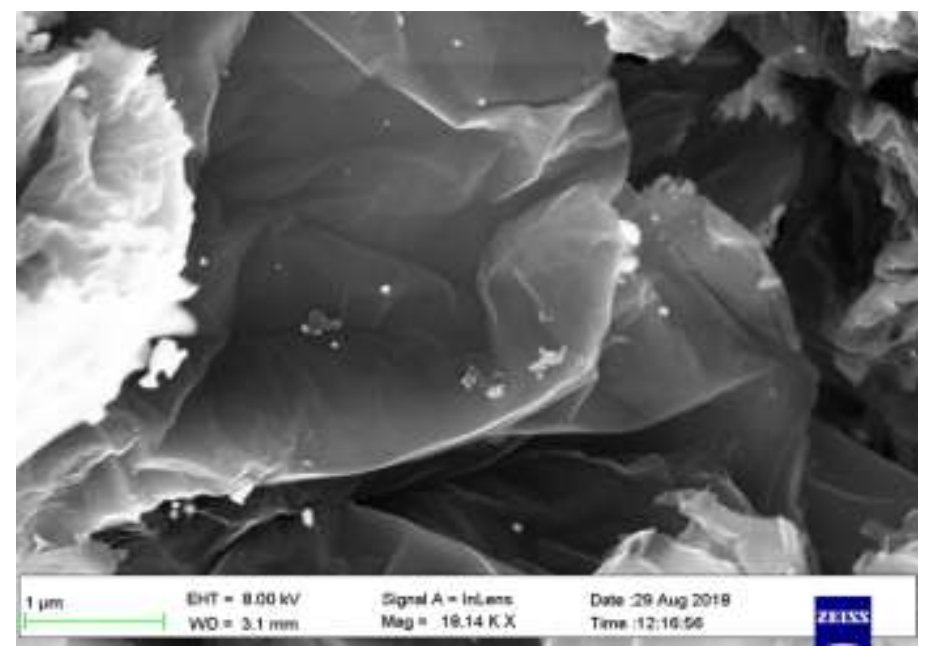

Fig.3. SEM images of Ag@G nanocomposite

\subsection{Cell assessment}

Fig. 4 displays the current density-voltage curves ( $\mathrm{J}$ $\mathrm{V}$ ) of the hybrid organic solar cells (composed of glass / ITO / TiO2 as an electron transport layer (ETL), $\mathrm{CH}_{3} \mathrm{NH}_{3}$ $\mathrm{Pbl}_{3}$ perovskite as active layers, thin Ag@G film as the $\mathrm{HTL}$ and carbon paste cathode as normal 1 sun AM 1.5 simulated solar irradiation. The cell shows significant efficiency with $\mathrm{VOC}=0.99 \mathrm{~V}, \mathrm{~J} \mathrm{SC}=16.1 \mathrm{mAcm}-2$, and $\mathrm{FF}=0.71$, equivalent to a PCE of $11.3 \%$ under standard 1 sun AM 1.5 simulated solar irradiation. Table 1 summarizes the parameters of photovoltaic devices obtained at 100 $\mathrm{mW} / \mathrm{cm}^{2}$ under AM $1.5 \mathrm{G}$ solar illumination. As shown from the information, to obtain a high-performance machine $[23,24]$, the existence of an effective hole conductor is critical.

\subsection{Photoluminescence measurement}

Photoluminecesnce $(\mathrm{PL})$ is one of the significant optical properties in the study of photovoltaic products, providing several parts of data including bandgap, chemical purity, and separation of charges [25]. Furthermore, measurements of PL quenching are a quick and easy way to explore separation of charges. If perovskite is in the vicinity with an electron acceptor (n-type quencher) or hole acceptor ( $p$-type quencher), electron or hole separation charges will reduce the $\mathrm{PL}$ intensity compared to the isolated state. The degree and effectiveness of load separation can be evaluated from the change in $\mathrm{PL}$ intensity.

Figure 5 demonstrates the shift in PL intensity in the lack and presence of $\mathrm{Ag@G}$ as p-type quenchers for the $\mathrm{CH}_{3} \mathrm{NH}_{3} \mathrm{Pbl}_{3}$ perovskites. There is a substantial reduction in $\mathrm{PL}$ intensity when both perovskite materials come into contact with Ag@G accepting hole. Load separation occurs well in the existence of inorganic hole conductors such as $\mathrm{Ag} @ \mathrm{G}$, as demonstrated by important PL quenching shown in Figure 5, PL quenching investigations are thus a helpful instrument for studying load segregation and obtaining data on interfacial contacts. Load separation occurs well in the presence of inorganic hole conductors such as Ag@G, as demonstrated by important PL quenching shown in Figure 5, PL quenching investigations are thus a helpful instrument for studying load segregation and obtaining data on interfacial contacts.

\section{Conclusions}

In summary, as a hole conductor for the perovskite solar cell, we have successfully developed (Ag@G) and a champion 30 efficiency of up to 11.3 percent has been shown. The under laid layer (Ag@G) can effectively remove the hole from the perovskite, promote the creation of homogeneous great environments and enhance surface performance. 


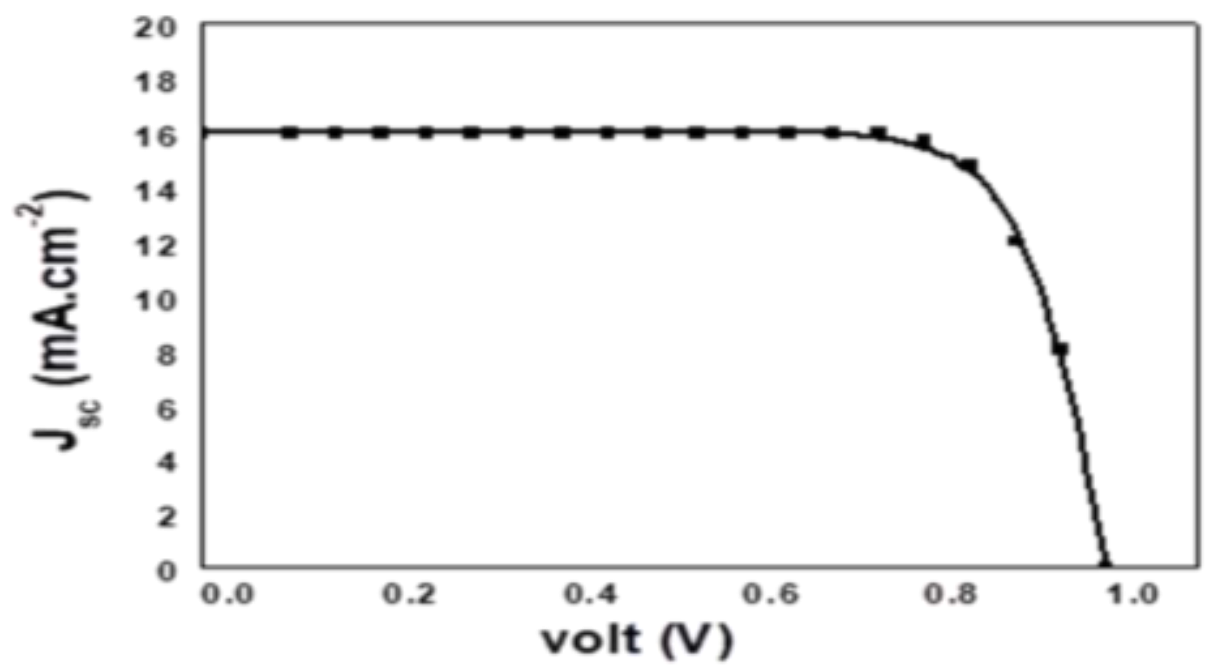

Fig.4. Current-voltage characteristics of PSCs containing HTLs based on Ag@G.

Table1. Photovoltaic characteristics of perovskite solar cells with various hole conductors

\begin{tabular}{|c|c|c|c|c|}
\hline $\begin{array}{l}\text { Hole conductor } \\
\text { layers }\end{array}$ & $\begin{array}{l}V_{o c}^{a} \\
\text { (V) }\end{array}$ & $\begin{array}{c}\mathrm{J}_{\mathrm{sc}}{ }^{\mathrm{a}} \\
(\mathrm{mA} / \mathrm{cm} 2)\end{array}$ & $\mathrm{FF}^{\mathrm{a}}$ & $\begin{array}{c}\mathrm{PCE}^{\mathrm{a}} \\
(\%)\end{array}$ \\
\hline PEDOT:PSS & 0.93 & 15.09 & 0.66 & 9.26 \\
\hline $\mathrm{GO}(0.5)$ & 0.99 & 15.02 & 0.67 & 9.96 \\
\hline $\mathrm{GO}(0.25)$ & 0.99 & 15.59 & 0.72 & 11.11 \\
\hline$A g @ G$ & 0.99 & 16.1 & 0.71 & 11.3 \\
\hline
\end{tabular}

${ }^{\mathrm{a}} \mathrm{All}$ the parameters of photovoltaics are the average of six devices.

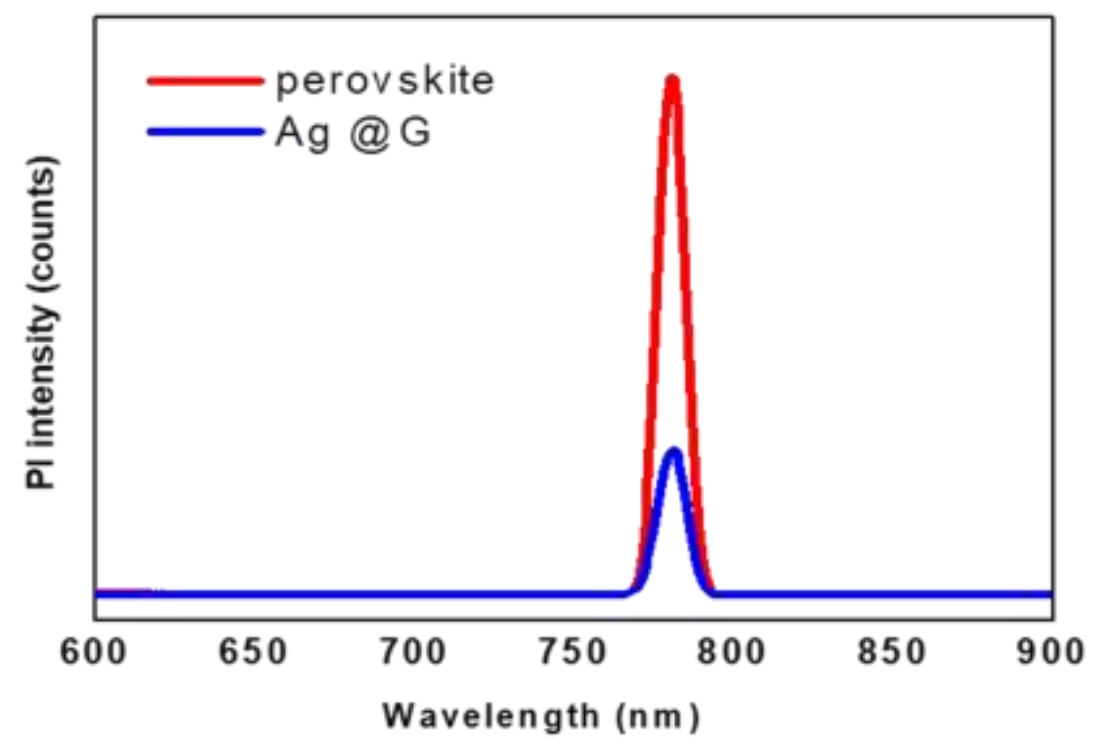

Fig.5. PL quenching behaviors for: (a) $\mathrm{CH}_{3} \mathrm{NH}_{3} \mathrm{Pbl}_{3} / \mathrm{Ag} @ \mathrm{G}$ system 


\section{References}

[1] M. Datt Bhatt, J. Sung Lee, New J. Chem., 41 (2017) 10508.

[2] H. Zhou, Q. Chen, G. Li, S. Luo, T.-b. Song, H.-S. Duan, Z. Hong, J. You, Y. Liu and Y. Yang, Science, 2014, 345,542-546.

[3] J.-H. Im, C.-R. Lee, J.-W. Lee, S.-W. Park and N.-

G. Park, Nanoscale, 2011, 3, 4088-4093.

[4] M. M. Lee, J. Teuscher, T. Miyasaka, T. N. Murakami and H. J. Snaith, Science, 2012, 338, 643647.

[5] H.-S. Kim, C.-R. Lee, J.-H. Im, K.-B. Lee, T. Moehl, A. Marchioro, S.-J. Moon, R. Humphry-Baker, J.-H. Yum, J. E. Moser, M. Gr"atzel and N.-G. Park, Sci. Rep., 2012, 2, DOI: 10.1038/srep00591.

[6] C. Chen, W. Zhang, J. Cong, M. Cheng, B. Zhang, H. Chen, P. Liu, R. Li, M. Safdari, L. Kloo, L. Sun, ACS Energy Lett. 2 (2017) 497.

[7] P. Kovacik, G. Sforazzini, A. G. Cook, S. M. Willis, P. S. Grant, H. E. Assender and A. A. R. Watt, ACS Appl. Mater. Interfaces, 2010, 3, 11-15.

[8] J. M. Ball, M. M. Lee, A. Hey and H. J. Snaith, Energy Environ. Sci., 2013, 6, 1739-1743.

[9] J. M. Frost, K. T. Butler, F. Brivio, C. H. Hendon, M. van Schilfgaarde and A. Walsh, Nano Lett., 2014, 14, 2584-2590.

[10] S. D. Stranks, G. E. Eperon, G. Grancini, C. Menelaou, M. J. P. Alcocer, T. Leijtens, L. M. Herz, A. Petrozza and H. J. Snaith, Science, 2013, 342, 341344.

[11] M. Saliba , T. Matsui , K. Domanski , J.Y. Seo , A. Ummadisingu , Science 354 (2016) 206.

[12] R.Rajeswari, H. Gurumallesh Prabu, M.Amutha, J. Appl. Chem. 10 (2017) 64.

[13] A. Agresti, S. Pescetelli, B. Taheri, A. EsaF Del Rio Castillo, L. Cin, F. Bonaccorso, A. Di Carlo, ChemSusChem 9 (2016) 2609.

[14] P. You, G. Li, G. Tang, J. Cao F. Yan, 2020, https://doi.org/10.1039/C9EE02324K.

[15] S. Tsarev, O. A. Kraevaya, S. Yu, L. Keith, J. Stevenson, P. A. Troshin, J. Mater. Chem. C, 8 (2020) 2419.

[16] J. V. Patil, S. S. Mali, C. K. Hong, Nanoscale, 11 (2019) 21824.

[17] Kim, H.-S.; Im, S. H.; Park, N.-G., Physical Chemistry C 118(2014) 5615-5625.

[18] N. Ahn, K. Kwak, M. S. Jang, H. Yoon, B. Yang, J. Lee, P. V. Pikhitsa, J. Byun, and M. Choi, Nature Communication 7, (2016) 13422.

[19] Y. Bi, E. M. Hutter, Y. Fang, Q. Dong, J. Huang, and T. J. Savenije, The Journal of Physical Chemistry Letters 7(2016)923.

[20] M. M. Lee, J. Teuscher, T. Miyasaka, T. N.

Murakami and H. J. 85 Snaith, Science, 338 (2012)

643.

[21] Panbo L, Ying H, Lei W. Mater Lett, 97 (2013) 173175.
[22] Y. Sang-Woo, C. Jae-Ryung, G. Myoung-Seon, Korean Chem. Soc. 35 (2014) 2251-2256.

[23] P. W. Liang, C. Y. Liao, C. C. Chueh, F. Zuo, S. T. Williams, X. K. Xin, J. Lin and A. K. Jen, Adv Mater, 26 (2014)3748.

[24] J. Y. Jeng, K. C. Chen, T. Y. Chiang, P. Y. Lin, T. D. Tsai, Y. C. Chang, T. F. Guo, P. Chen, T. C. Wen and Y. J. Hsu, Adv. Mater., 26 (2014)4107. [25] N. C. Greenham , R. H. Friend, D. D. C. Bradley, Adv. Mater. 6 (1994) 491. 